\title{
Is the ICT use for health purposes in Slovenia linked to better health?
}

\author{
Andrej Kirbiš \\ University of Maribor, Faculty of Arts, Maribor, Slovenia \\ andrej.kirbis@um.si
}

\section{Abstract}

Introduction: In recent years, the use of ICT for health purposes has become increasingly common and popular among the residents of developed societies, including the elderly. The development of ICT in health and health care can contribute to disease prevention and control for those who need health information and services the most - the elderly and those with poor health. For this reason, it is vital to examine whether the search for information using ICT technology is associated with better health. Methods: In our study, we were interested in: 1) the frequency of searching for information with ICT; 2) the link between ICT seeking health information and health status; 3 ) the moderating role of age for the link between the frequency of searching for health information and the health status of the individual, and 4) whether the search for health information is related to the health status after controlling the sociodemographic determinants of ICT use. We used a representative national sample of the adult population of Slovenia from $2018(\mathrm{~N}=1047)$. We performed descriptive and multivariate analyses. Results: We found that in Slovenia, 1) the majority of the population uses ICT to obtain health information; 2) those with poorer health most often use ICT for health purposes; 3) age impacts the link between information seeking and health status; and 4) when controlled for sociodemographic determinants in the multivariate model, health status proved not to be statistically significantly associated with ICT use for health purposes. Discussion and conclusions: ICT can potentially improve the Slovenian population's health and access to health services. At the same time, we emphasise that better health can also enable easier and more efficient access, search and use of ICT health information. Further research is needed to examine whether there is a causal effect of ICT search and use of health information on health outcomes. It is also crucial that future studies examine whether the health effects are 
mainly for specific dimensions of health or whether they improve overall health status. The paper concludes with a discussion on the importance of ICT in health services and its importance for positive population health outcomes, especially for vulnerable groups. We also provide suggestions for achieving a more well-informed population concerning the opportunities offered by ICT in health promotion and disease prevention.

Keywords: health inequalities, eHealth, ICT use for health purposes, the elderly.

\section{Introduction}

The use of information and communication technology (ICT), including the Internet and smartphone apps, is becoming an important source of information related to health. The term electronic health ("E-health or eHealth) refers to measures to support health care through ICT (Rockmann and Gewald 2015: 505). In modern societies, eHealth services are increasingly becoming patient and consumer-oriented, enabling consumers to actively engage in their health and well-being by accessing health resources via the Internet (Rockmann and Gewald 2015). As early as 2009, for example, 61\% of adults in the United States used the Internet to access information about their illnesses and treatment options (Fox and Jones, 2009; in Rockmann and Gewald 2015: 510).

An analysis of the use of eHealth solutions in Slovenia (Rant and Stanimirović 2020) before the COVID-19 pandemic showed that between 2016 and 2019, the use of eHealth services increased. For example, the proportion of e-prescriptions and e-referrals in 2019 exceeded $90 \%$ of the total number of prescriptions and referrals. The share of e-referrals doubled during the period under review, from $45 \%$ to $94 \%$. The use of the zVEM web portal also increased during the same period.

Research on the use of ICT shows that many factors influence the search for health-related information. The frequency of information search varies, among other things, according to age and gender, but also health status, which is the main factor of interest in our study.

Besides other factors, it is vital to examine whether the use of ICT for health purposes is unequally distributed according to users' health status. From the point of view of equity in health services, one of the goals is equality of access and use of ICT for health purposes (regardless of individual's characteristics such as age, gender, socioeconomic status or health). However, evidence suggests that there are inequalities in access to health care services. For example, socially deprived groups have worse health and poorer access to health services (Riley 2012; Thomas 2017; Committee on Health Care Utilization and Adults with Disabilities 2018).

Research on ICT use similarly indicates a link between one's health and health-related ICT use. A survey of a sample of Norwegians aged 40 and over 
found that respondents who reported having a disease were more likely to use the Internet for health information (Wynn et al. 2020). In several other studies, poorer health has similarly been positively associated with the frequency of health-related use of the Internet. A U.S. survey of 21-year-olds and older found that those with two, three, or more chronic illnesses were more likely to use the Internet to seek health information (Wagner et al. 2004). Those with poorer subjective health also more frequently search for health information on the Internet (Baker et al. 2003). Similar findings were detected in a study of type 1 and type 2 diabetes; ICT use for health purposes was more common among those with poorer self-rated health (Hansen et al. 2019).

It needs to be noted that the results of the studies are not entirely consistent. In the aforementioned Norwegian study, for example, self-rated health did not prove to be statistically significantly related to the frequency of use of eHealth services (Wynn et al. 2020). In a study of seven European countries, Andreassen and colleagues (2007) found that respondents with poorer subjective health reported less frequent health-related Internet use. On the other hand, those with long-term chronic illness or disability reported more frequent health-related Internet use.

Research in some countries indicates that individuals with poorer health use the Internet for health purposes more frequently than their healthier counterparts. We examine whether this also holds in Slovenia. We also analysed the potential moderating role of age for the relationship between the frequency of seeking health information and an individual's subjective health status.

\section{Methods}

In the present study, we examined the frequency of searching for health-related information online and in smartphone apps. We compared three age groups: young people (18-34 years), adults (35-64 years) and the elderly (aged 65 and over).

We analysed a representative sample of the population of Slovenia using the Slovenian Public Opinion survey (Hafner Fink et al. 2019). Survey data were collected between 14 March 2018 and 12 June 2018. The sample included individuals over 18 living in private households, regardless of their nationality, citizenship, language or legal status in Slovenia. We performed bivariate analyses with chi-square tests and multivariate analysis.

The following dependent variable was examined: "How often did you search for health-related information online or in apps?" ( $1=$ never; 2 = less than once a month; $3=$ at least once a month; $4=$ at least once a week; $5=\mathrm{ev}$ ery day; $6=$ almost every day several times a day). Due to the uneven distribution of answers, values from 4 to 6 were recoded into a single category (at least once a week).

We included several control variables in our multivariate model. Specifically, we included age, gender, and partner status. Respondents' age in years 
was recoded into three age categories (18-34 years, 35-64 years, and 65 years and older). In addition to gender ( $1=$ male; $2=$ female), partner status was also added in our model, which was measured with the question: "Are you married or do you have a permanent partner? Do you share a joint household?" (1= yes, I live in a joint household with my spouse or permanent partner; $2=\mathrm{I}$ am married or have a permanent partner, but we do not live in a joint household; 3 $=$ no, I am not married, I do not have a permanent partner). Values were recoded into two categories $(1=$ respondent has a permanent partner; $2=$ respondent has no permanent partner).

Finally, we were interested in whether the subjective health status of respondents was related to the frequency of use of health information online or in applications. We measured health with a standard self-rated health indicator: "Would you say your health in general, is ...? ( $1=$ poor; $2=$ satisfactory; $3=$ good; 4 = very good; $5=$ excellent). Values were recoded into three groups $(1=$ poor/satisfactory; 2 = good; 3 = very good/excellent).

\section{Results}

Figure 1 shows the frequency of searching for health information online or in applications by the Slovenian public. In 2018 , more than $14 \%$ of Slovenians never searched for health information online or in applications. The largest proportion of respondents $(33.7 \%)$ searched for information at least once a month. The second largest group reported weekly or more frequent searches for information, followed by searching for information less than once a month (each of the two answers was chosen by about one in four respondents).

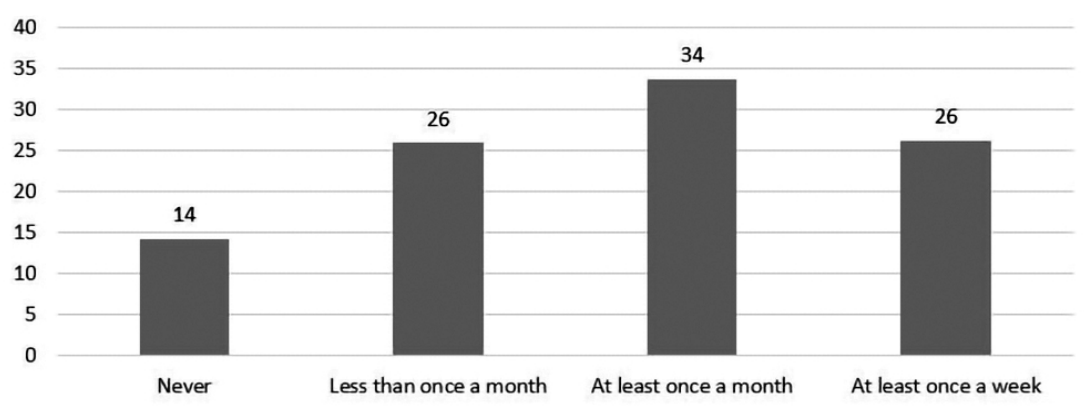

\section{Figure 1: Frequency of searching for health information online or applications among the Slovenians population Source: Slovenian Public Opinion 2018/1 (Hafner Fink et al. 2019).}

Figure 2 shows the frequency of information search by age group. We see that the proportion of those who never use the Internet/apps to search for health information increases with age. While this share is the lowest in the youngest age group (10.5\%), it increases to $13.4 \%$ in the adult group, with the highest proportion of non-users being among the elderly, with more than twice 
as many non-users (26.5\%) as among young people. At the same time, the categories of the most frequent information seekers are very comparable by size between age groups; the youngest age group has the largest proportion of most frequent users (27.9\%), followed by the oldest age group (26.5\%) and the middle-age group (25.4\%). The chi-square test showed that differences between age groups in the frequency of health-related information search were statistically significant $(\mathrm{p}<0.05)$.

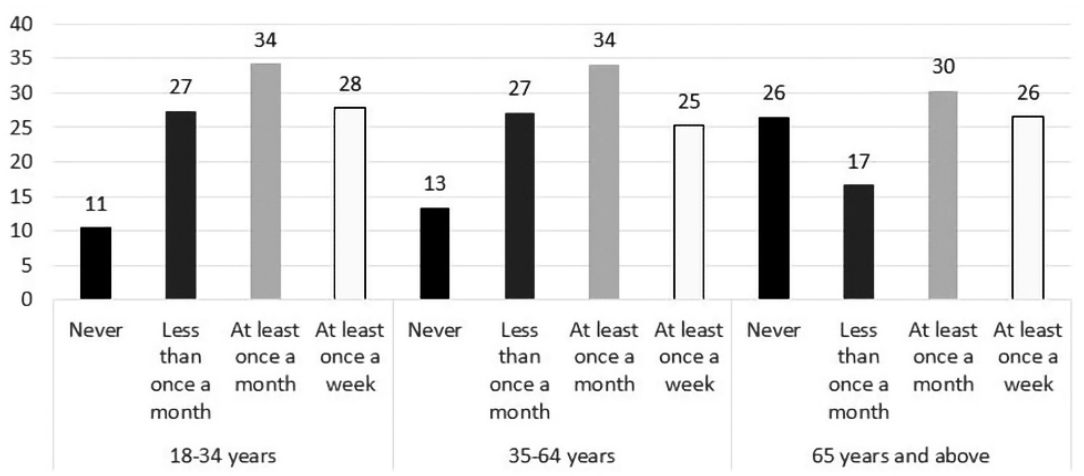

Figure 2: Frequency of searching for information by age group

Source: Slovenian Public Opinion 2018/1 (Hafner Fink et al. 2019).

Figure 3 shows the frequency of information search according to the respondents' self-rated health. The results show that the proportion of those who never use the Internet/apps to search for health information decreases with better health, indicating that among the healthiest respondents, there is the smallest proportion of non-users. On the other hand, the proportion of the most frequent searchers (who search for information at least weekly) is among the least healthy group (30.5\%), and the lowest proportion of frequent searchers is in the two remaining groups (around 1 in 4 in each group). The chi-square test showed that differences between health groups were statistically significant $(\mathrm{p}<0.05)$.

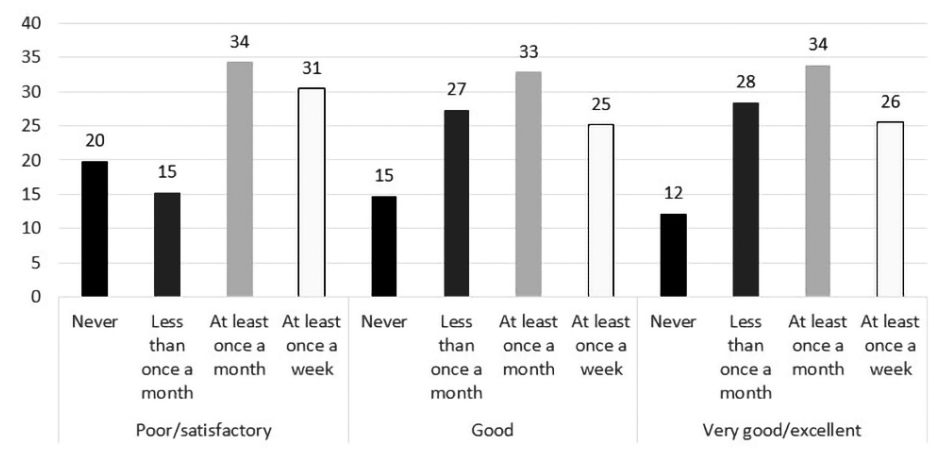

Figure 3: Frequency of searching for information by self-rated health status Source: Slovenian Public Opinion 2018/1 (Hafner Fink et al. 2019). 
Figure 4 shows the moderating role of age for the relationship between the frequency of health-related search and an individual's health status. The results show that in the youngest and oldest age group, the search for health information is associated with better health (see positive coefficients in Figure 4) and in the middle age group with poorer health. We note that none of the associations reached the level of statistical significance ( $p>0.05)$.

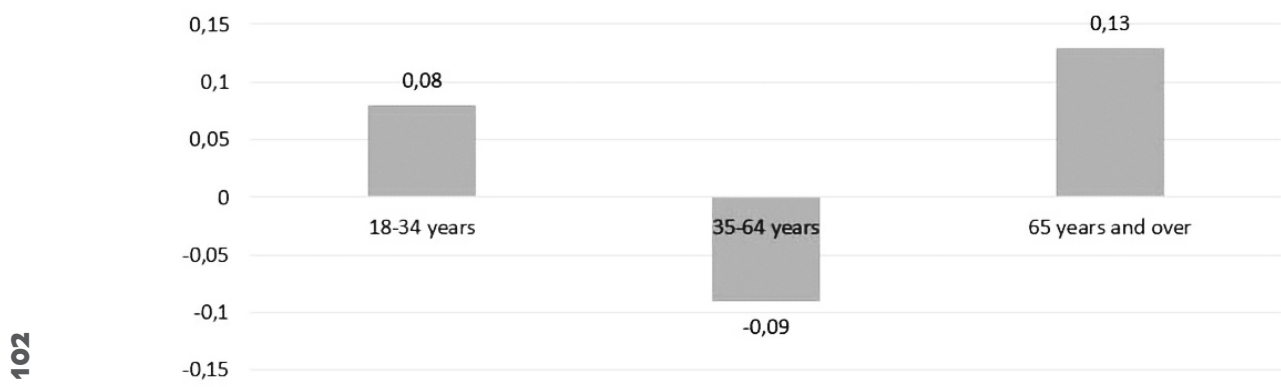

\begin{abstract}
Figure 4: Moderating role of age for the relationship between the frequency of searching for health information and the self-rated health Source: Slovenian Public Opinion 2018/1 (Hafner Fink et al. 2019). Note: Data indicates coefficient between health information search and self-rated health.
\end{abstract}

We also performed a regression analysis predicting the frequency of health-related information searches while controlling for the demographic variables. We were interested in whether better health was associated with more frequent search for health information when controlling for other variables. The analysis showed that of the four variables included in our model, the only statistically significant predictor of more frequent health information search was female gender $(\beta=0.09 ; \mathrm{p}<0.05)$. The other three predictors did not prove statistically significant, including self-rated health.

\title{
Discussion
}

Based on our study, we can summarize that there are differences in the frequency of searches for health information online and on apps by some determinants in Slovenia. Three out of five people search for health information online or apps at least monthly, and just under $15 \%$ of the population are non-seekers. Information is more often searched for by the elderly (but their group also has the largest proportion of non-seekers), women and those with poorer health (the largest proportion of non-seekers is also among them). We also find that age moderates the relationship between the frequency of health information seeking and the health status of the individual. In the youngest and oldest age groups, the search for health information is associated with better health (though statistically insignificantly). Multivariate analysis of the factors pre- 
dicting information search revealed that the female gender was the only significant predictor impacting the frequency of health information search.

Based on our results research, we can conclude that it is important to raise awareness of decision-makers and the public about the importance of access to the Internet, about the resources needed to search for health-related information online or via apps and to inform decision-makers on demographic and other factors contributing to inequalities in ICT use for health purposes. It is also necessary to be aware that ICT use can contribute to improving the health of the Slovenian population and access to health services. On the other hand, better health can also help (enable) an individual to more easily access and efficiently use ICT for health information proposes. In any case, future research is needed to examine the causal effect of ICT use and the use of health information on personal and public health. At the same time, researchers should examine whether the (potential) positive effects hold mainly for particular dimensions of health (e.g., physical symptoms, mental health) or overall health.

Strengthening intergenerational cooperation, e.g. through various programs, where young people would share their ICT knowledge with the elderly, while the latter could share their life experiences and knowledge with young people, could also encourage improvements in the health of both age groups.

\section{Conclusions}

We can conclude that the development and use of ICT in health information and healthcare services has played an important role in healthcare in recent years. Evidence suggests it may contribute to better health, including for more vulnerable groups. Proposals for strengthening the access to information with the possibilities and potential offered by ICT in the area of health promotion include informing the public in various popular media outlets, but also by personal physicians and other health professionals, for example, by health workers in reference clinics. In this way, older and other more vulnerable groups could be informed in more detail about how the use of ICT can improve their access to healthcare services and help maintain and enhance patients' health, and potentially even prevent disease.

\section{References}

ANDREASSEN, H. K., BUJNOWSKA-FEDAK, M. M., CHRONAKI, C. E., DUMITRU, R. C., PUDULE, I., SANTANA, S., VOSS, H., \& WYNN, R. (2007). European citizens' use of e-health services: A study of seven countries. BMC Public Health, 7(1), 53. https://doi.org/10.1186/1471-2458-7-53

BAKER, L., WAGNER, T. H., SINGER, S., \& BUNDORF, M. K. (2003). Use of the internet and e-mail for health care information: Results from a national survey. JAMA, 289(18), 2400-2406. https://doi.org/10.1001/jama.289.18.2400 
COMMITTEE ON HEALTH CARE UTILIZATION AND ADULTS WITH DISABILITIES. (2018). Health-care utilization as a proxy in disability determination. Consensus study report. The National Academies Press. https://doi.org/10.17226/24969

HAFNER FINK, M., HOČEVAR, M., GROŠELJ, D., URŠIČ, M., ZAVRATNIK, S., \& MEDVED, P. (2019). Slovensko javno mnenje 2018/1. https:// doi.org/10.17898/ADP_SJM181_V1

HANSEN, A. H., BRADWAY, M., BROZ, J., CLAUDI, T., HENRIKSEN, Ø., WANGBERG, S. C., \& ÅRSAND, E. (2019). Inequalities in the use of ehealth between socioeconomic groups among patients with type 1 and type 2 diabetes: Cross-sectional study. Journal of Medical Internet Research, 21(5), e13615. https://doi.org/10.2196/13615

RANT, Ž., \& STANIMIROVIĆ, D. (2020). Analiza uporabe rešitev ezdravja v sloveniji: Izzivi in prihodnje usmeritve. In 39th international conference on organizational science development (pp. 645-661). University of Maribor Press. https://doi.org/10.1869o/978-961-286-388-3.51

RILEY, W. (2012). Health disparities: Gaps in access, quality and affordability of medical care. Transactions of the American Clinical and Climatological Association, 123, 167-174.

ROCKMANN, R., \& GEWALD, H. (2015). Elderly people in ehealth: Who are they? Procedia Computer Science, 63, 505-510. https://doi.org/10.1016/j. procs.2015.08.376

THOMAS, L. (2017). Poor health: Poverty and scarce resources in U.S. Cities. Pittsburgh Post-Gazette. https://newsinteractive.post-gazette.com/longform/stories/poorhealth/1/

WAGNER, TODD, BAKER, LAURENCE, C., BUNDORF, KATE, \& SINGER, S. (2004). Use of the internet for health information by the chronically ill. Preventing Chronic Disease, 1.

WYNN, R., OYEYEMI, S. O., BUDRIONIS, A., MARCO-RUIZ, L., YIGZAW, K. Y., \& BELLIKA, J. G. (2020). Electronic health use in a representative sample of 18,497 respondents in Norway (the seventh TROMS $\varnothing$ study part 1): Population-based questionnaire study. JMIR Medical Informatics, 8(3), e13106. https://doi.org/10.2196/13106 